\title{
Juego en primera infancia
}

Aproximación al significado otorgado por educadoras de párvulosi

Play in Early childhood

Approach to the meaning given by Nursery Teachers

Jogo em primeira infância

Aproximação ao significado dado por Educadoras de Crianças

\section{DOI: https://doi.org/10.18861/cied.2021.12.1.3063}

Carmen Patricia Mena Bastias

Universidad del Bio-Bio

cmena@ubiobio

ORCID: 0000-0002-6905-0079

Carolina Bernarda Flores Lueg

Universidad del Bio-Bio

Chile

cflores@ubiobio.cl
ORCID: 0000-0001-5219-0617

\section{Patricia Eugenia Arteaga González}

Universidad del Bio-Bio

Chile

parteaga@ubiobio.cl
ORCID: 0000-0002-7848-6894

Dalys Saldaña Espinoza

Universidad San Sebastián

Chile

dalys.saldana@uss.cl

\section{Eliana Lucía Navarrete Troncoso}

Universidad del Bio-B

Inavarre@ubiobio.cl $0891-8903$

Recibido: $17 / 04 / 2020$

Cómo citar: Mena Bastías, C. P., Flores Lueg, C. B., Arteaga González, P. E., Saldaña Espinoza, D., \& Navarrete Troncoso, E. L. (2021): Juego en primera infancia. aproximacion al significado otorgado por educadoras de parvulos. Cuadernos de

Investigación Educativa, 12(1). https://doi.org/10.18861/cied.2021.12.1.3063

\section{Resumen}

El juego como actividad natural del ser humano -fundamentalmente en sus primeros años de vida- adopta una relevancia resultados de punto de vista pedagógico a nivel de la educación infantil. Al respecto, este trabajo presenta los principales desempeñan su labor con párvulos menores de tres años. La investigación se llevó a cabo bajo una metodología cualitativa y se empleó la Fenomenología Hermenéutica como método. Participaron seis profesionales que desempeñan su labor con de producción de información se empleó la entrevista en profundidad, analizada a partir de un proceso de categorización mixto con apoyo del software Atlas ti v.8. En los resultados se destaca que las educadoras, a nivel de conciencia, tienen claridad para conceptualizar el juego, atribuyéndole una significativa valoración como medio para el aprendizaje, pero en su implementación se visualiza la instrumentalización de esta actividad.

\section{Abstract}

The play, as a natural activity of the human being, mainly during the first years of life, acquires a key relevance from the pedagogical point of view at the level of early childhood education. In this regard, this work presents the main results of a study who aimed at finding out the meaning attributed to the play by nursery teachers a dutive method a qualtative messionals who work with pre-

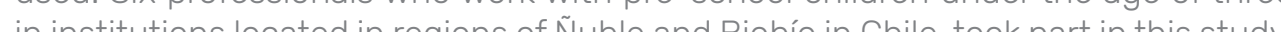
As information production techniqu an in-depth interview was used, anatyzed as infor The resuls highlight that nursery teachers, at a conscious level have clarity to

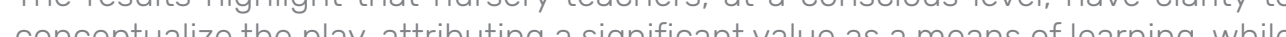
in its implementation, the instrumentalization of this activity is visualized.

Keywords: Early childhood, play, pre-school teacher, educational strategies

\section{Resumo}

O jogo, como atividade natural do ser humano fundamentalmente em seus primeiros anos de vida, adota uma relevância chave do ponto de vista pedagógico no nível da educação infantil. Quanto a isso, esse trabalho apresenta os principais resultados de uma análise que teve como alvo indagar sobre o significado atribuído ao jogo por educadoras que desempenham seu trabalho com crianças menores de três anos. A pesquisa foi realizada conforme uma metodologia qualitativa sendo utilizada a Fenomenologia Hermenêutica como método. Participaram dela seis profissionais que desempenham seu trabalho com crianças menores de três anos em instituições educacionais localizadas nas regiões de Ñuble e Biobío no Chile. Como técnica de produção de informação foi empregada a entrevista em profundidade, analisada a partir de um processo de categorização misto com apoio do software Atlas ti v.8. Nos resultados salienta que, em nível de consciência, as educadoras têm clareza para conceituar o jogo, atribuindo-Ihe significativa importância como meio de aprendizagem, porém em sua implementação é percebida a instrumentalização dessa atividade.

Palavras-chave: Primeira infância, jogo, docente pré-escolar, estratégias educacionais 


\section{Introducción}

En la actualidad, la educación parvularia o educación infantil se ha constituido en uno de los niveles formativos de alta relevancia para las diferentes políticas sociales, educativas y económicas que se han venido implementando desde hace algún tiempo en diversos paises latinoamericanos (Bravo y Morales, 2012). Estas acciones se fundamentan en los diversos aportes teóricos y empíricos emanados desde las neurociencias, los que dan cuenta de la relevancia de los seis primeros años de vida en el desarrollo posterior del ser humano (Katz, 2005: Mineduc, 2014; Ramírez, Patiño y Gamboa, 2014).

Dentro de las políticas referidas al mejoramiento de la educación parvularia en Chile se destaca la actualización realizada en el año 2018 al Marco Curricular. En sus fundamentos, principios pedagógicos y orientaciones para los contextos de aprendizaje se enfatiza en el juego como principal actividad del ser humano en los primeros años de vida, explicitando que "el juego es, a la vez, expresión de desarrollo y aprendizaje y condición para ello" (Mineduc, 2018, p. 32), en tanto que esta actividad natural impulsa, en el niño, el desarrollo de las funciones cognitivas superiores, la afectividad, la socialización, la apropiación de la realidad y su adaptación a ella. Asimismo, esta acción tan trascendental dentro de los primeros años de vida es reconocida como uno de los derechos de los niños (Ministerio de Relaciones Exteriores de Chile, 1990). Por consiguiente, las prácticas de juego no solo deben ser impulsadas desde las políticas públicas para la infancia sino que, al mismo tiempo, se requiere asegurar que este derecho sea cumplido.

El juego adquiere un significado fundamental pues es un proceso que abre permanentemente posibilidades para la imaginación, el gozo, la creatividad y la libertad (Mineduc, 2001). Es en este sentido que una pedagogía infantil integradora y respetuosa de sus caracteristicas debe relevar al juego como actividad privilegiada de los párvulos. Por ello, se concuerda con Sarlé (2008), cuando señala que,

al jugar el niño aprende y desarrolla su pensamiento, su imaginación y su creatividad. Esta actividad le provee de un contexto dentro del cual puede ensayar formas de responder a las preguntas con las que se enfrenta, construir conocimientos nuevos, reelaborar sus experiencias, tomar conciencia de si mismo y apropiarse de la realidad. Del mismo modo, el juego le permite comunicarse, cooperar con otros y ampliar el conocimiento que tiene del mundo social. (p. 20)

Por su parte, y en esta misma línea Lansdown (2013) expone que "el juego también es una dimensión clave de la educación, necesaria para alcanzar el mejor estado de salud posible, que es un componente indispensable del desarrollo óptimo del niño". (p. 2)

Por consiguiente puede desprenderse que el juego -además de ser una actividad natural de los niños- es un derecho universal y, como tal, requiere de reconocimiento y legitimidad por parte del sistema educativo y de las personas clave que están junto a ellos. No obstante, se concuerda con Lansdown (2013) cuando sostiene que, 
a pesar del carácter central del juego respecto a la salud, el bienestar y el desarrollo de los niños, raramente los gobiernos lo toman en cuenta seriamente. Ya sea por omisión (desatendiendo la obligación de proteger los espacios y oportunidades para el juego y hacer inversiones para su creación) o por actos deliberados (la imposición de excesivas restricciones a la vida de los niños), en todo el mundo son muchos los niños que no consiguen realizar plenamente su derecho al juego. (p. 2)

Si bien el juego se constituye en concepto central para la educación infantil o parvularia en tanto le otorga un sello distintivo dentro del sistema escolar, desde hace algún tiempo esta actividad natural de los niños ha sido desplazada o escasamente valorada por las propias educadoras de párvulos, dejando de promoverse e intencionarse inclusive desde edades muy tempranas. Al respecto, López de Maturana (2017) advierte que la tendencia ha sido por muchos años la de ver a la educación parvularia como educación preescolar, con todo lo que eso implica: niños sentados en sillas, aprendiendo letras y números a una edad en que solo buscan explorar a través del juego, descubrir el mundo con sus ojos y sus manos. Sumado a lo anterior, Durán y Pulido (2018) advierten que "a pesar de que muchas maestras entienden la importancia del juego en la infancia, siguen desarrollando acciones que lo limitan, restringen o instrumentalizan" (p. 227). Por su parte, el Comité sobre los Derechos del Niño de las Naciones Unidas (2013) también señala que el juego se considera con frecuencia un elemento no esencial y frente a ello enfatiza que esta actividad corresponde a una dimensión fundamental y vital del placer de la infancia, asi como un componente indispensable del desarrollo físico, social, cognitivo, emocional y espiritual.

Considerando la relevancia que adopta esta actividad en los primeros años de vida de un ser humano y la necesidad de que sea revalorizada como una acción espontánea que favorece el aprendizaje integral y el desarrollo armónico en forma natural, en este trabajo nos propusimos indagar sobre el significado que le atribuyen al juego educadoras de párvulos que desempeñan su labor con niños menores de tres años.

\section{Marco Teórico}

\section{El juego y su importancia en la primera infancia}

La actividad lúdica en la primera infancia genera beneficios, entre ellos la creación de un sentimiento verdadero de sí mismo y del otro y un acercamiento a las primeras ideas sobre el lenguaje y el mundo físico, además de que favorece el desarrollo de sus habilidades sociales y de reflexión. Según Brooker (2013), "el juego contribuye de manera significativa a todos los aspectos del desarrollo infantil porque les ayuda a adquirir numerosas aptitudes y competencias tempranas" (p.17). Por ejemplo, los bebés aprenden a conocerse a sí mismos y al mundo en que viven mediante interacciones lúdicas con los adultos.

Si bien es cierto que el juego ha sido definido desde diversas perspectivas, concordamos con el Comité sobre los Derechos del Niño de las Naciones Unidas (2013) cuando lo conceptualiza como, 
todo comportamiento, actividad o proceso iniciado, controlado y estructurado por los propios niños; tiene lugar dondequiera y cuando quiera que se dé la oportunidad. Las personas que cuidan a los niños pueden contribuir a crear entornos propicios al juego, pero el juego mismo es voluntario, obedece a una motivación intrínseca y es un fin en sí mismo, no un medio para alcanzar un fin. El juego entraña el ejercicio de autonomía y de actividad fisica, mental o emocional, y puede adoptar infinitas formas, pudiendo desarrollarse en grupo o individualmente. (p. 6)

En consecuencia, al jugar los niños aprenden y desarrollan su pensamiento, su imaginación y su creatividad. Esta actividad les provee un contexto que les permite ensayar formas de responder a las preguntas con las que se enfrentan y construir conocimientos nuevos; les ayuda a reelaborar sus experiencias y es un importante factor de equilibrio y dominio de si mismos. Al mismo tiempo les permite comunicarse, cooperar con otros y ampliar el conocimiento que tienen del mundo social (Sarlé, 2008).

\section{El juego desde el ámbito curricular y el rol del adulto}

Uno delosaspectoscentralesaconsiderarenunaeducacióninfantileminentemente humanista y potenciadora corresponde a la comprensión de los fundamentos y principios que le dan sustento. Particularmente en las Bases Curriculares de la Educación Parvularia (Mineduc, 2018), marco curricular vigente para este nivel educativo en Chile, se definen los siguientes principios pedagógicos: bienestar, actividad, singularidad, potenciación, relación, unidad, significado y principio del juego. Especial atención adopta este último ya que enfatiza, por una parte, la centralidad de esta actividad natural del ser humano en su desarrollo integral y, por otra parte, el carácter lúdico que deben tener las experiencias educativas y situaciones de aprendizaje que se ofrecen a los párvulos, principalmente en sus tres primeros años de vida. Esto se debe a que en este periodo de la vida requieren de experiencias de aprendizaje que permitan satisfacer sus necesidades básicas y entre ellas se encuentra el juego.

Para dar respuesta a lo anterior resulta fundamental la generación de un espacio-ambiente lúdico, seguro y provocador, donde primen oportunidades de movimiento, exploración, encuentro y relación, de tal manera que se constituyan en ambientes promotores de aprendizajes que promuevan el proceso identitario de los párvulos (Fusté y Bonastre, 2014). Al respecto, es importante subrayar que dentro del espacio y ambiente áulicos el rol que cumpla el educador y la actitud hacia el proceso educativo de los niños adoptan un valor trascendental, pues por una parte el educador tiene la responsabilidad de dotar al ambiente educativo de los elementos oportunos que favorezcan el aprendizaje pero, al mismo tiempo, debe ser capaz de acompañar a los párvulos en su proceso de aprendizaje deteniéndose a observar, leer y comprender los juegos que llevan a cabo espontáneamente. Esto se debe a que la observación rigurosa de la acción espontánea ofrece la posibilidad de "recoger información útil sobre la evolución del niño y la niña y recibir sugerencias valiosas para activar los estímulos más convenientes en ese determinado momento" (Borghi, 2010, p. 183). 


\section{Perspectivas curriculares en la educación parvularia y juego infantil}

Dentro de los discursos actuales sobre pedagogía para la educación infantil a nivel internacional y nacional se evidencian ciertas perspectivas curriculares ampliamente referenciadas por educadoras de párvulos y otros actores del sistema escolar chileno. Entre dichas perspectivas se destacan, por ejemplo, la Pedagogía Waldorf y la Pedagogía Pikler, cuyos orígenes se remontan a inicios y mediados del siglo XX en Europa Occidental.

\section{Pedagogía Waldorf y juego infantil}

La Pedagogía Waldorf se comienza a materializar en el año 1919 con la primera escuela conocida como Freie Waldorfschule, implementada en Stuttgart (Alemania) por Rudolf Steiner, bajo los preceptos del movimiento antroposófico, del cual se le reconoce como su fundador (Quiroga, 2014). Para Steiner (1973), la antroposofía es entendida como "un camino de conocimiento que pretende guiar lo espiritual en el ser humano a lo espiritual del universo" (p. 9), fundamento central de esta propuesta pedagógica. Posteriormente se expandió al resto de Europa y Latinoamérica, y se instauró en Chile hace cuarenta años.

Dentro de los principios educativos de la Pedagogía Waldorf se encuentra la consideración de la estructura madurativa de la biografía humana, la que para Steiner (1997) se divide en septenios. El primer septenio va de o a 7 años, cuya cualidad anímica es el querer o la voluntad. El segundo septenio, de los 7 a los 14 años, cuya cualidad es el sentir, y el tercer septenio va de los 14 a los 21 años, caracterizada por el pensar (Quiroga e Igelmo, 2013). La primera etapa adopta un significado relevante en tanto durante la misma se desarrollan tres habilidades básicas tales como el andar, el hablary el pensar. Dentro de este periodo educativo el ambiente fisico y la figura del educador se constituyen en factores clave, pues el jardin infantil se concibe como un lugar en el que se desarrollan diversas actividades con sentido y donde los párvulos aprenden jugando en el entendido de que esta acción favorece la maduración del desarrollo psicomotor que logra conquistar durante los primeros años de su vida (Quiroga e Igelmo, 2013). Cabe destacar que el juego siempre es libre, no hay juego reglado u organizado por el adulto, pero para intencionar el desarrollo de los párvulos las aulas Waldorf disponen de materiales específicos elaborados a base de elementos y formas naturales. Asimismo, el ambiente de aprendizaje representa una continuación del hogar y promueve la actividad imitativa de los educandos en torno a acciones maternas y paternas.

\section{Pedagogía Pikler y juego motor}

La Pedagogía Pikler surge a partir de los estudios científicos de la Dra. Emmi Pikler (1902- 1984), los que tenían como propósito demostrar su visión del niño como ser autónomo. Esta pediatra húngara se centró en la observación, reflexión y registro sistemático de las actividades cotidianas de cientos de niños menores de tres años internados en un hogar infantil, y que recibian cuidados prolongados debido a la enfermedad de la madre, su fallecimiento u otros motivos (Pikler, 1984). Este centro de atención, ubicado en la calle Lóczy (Budapest), a partir de 1946 pasó a denominarse Instituto Lóczy, cuyo objeto de interés fue el desarrollo de la motricidad estudiada dentro de las actividades cotidianas de los niños (Pikler, 1984). 
Siguiendo a Herrán (2013), esta perspectiva pedagógica se sustenta en los siguientes cuatro principios básicos:

- Valoración y estabilidad en las relaciones afectivas privilegiadas entre el adulto y el niño;

- Valoración y promoción de la autonomía en el movimiento y en la actividad infantil;

- Necesidad de ayudar al niño en la toma de conciencia de sí mismo y de su entorno de acuerdo con su nivel de desarrollo e.

- Importancia de un buen estado de salud, como resultado de la buena aplicación de los principios anteriores.

En lo que respecta a la labor pedagógica y al juego propiamente tal, Ormaza (2016) señala que, desde sus orígenes, en su implementación se han considerado todas las condiciones y elementos que constituyen la actividad de juego, tanto para cada grupo como para cada niño en particular. Entre ellas, esta autora destaca:

- Distribución del tiempo. Solo se expone al niño a situaciones de actividad autónoma cuando sus necesidades básicas están satisfechas, porque puede aprovechar aquellas plenamente y ser feliz en ellas. Para ello, los momentos de juegos se organizan con gran flexibilidad respetando el ritmo de cada niño.

- El espacio. Se incluyen situaciones en las que el niño puede aprender a dominar movimientos sin ningún tipo de peligro, lo que le da seguridad $y$, al mismo tiempo, restringe las intervenciones reiteradas del adulto.

- Los objetos y los materiales de juego. Cada elemento responde a las posibilidades de desarrollo del niño de acuerdo con la evolución de su interés.

- Las actividades de las educadoras. Se centran en generar las condiciones óptimas, que respeten el ritmo de los niños, que promuevan su autonomía y proactividad para evitar interferir de manera directa en su juego. Solo en tres tipos de circunstancias el adulto tiene una intervención más activa: cuando el niño se encuentra frente a una situación de dificultad elevada, cuando hay peleas y cuando hay señales que indican aburrimiento o cansancio (Ormaza, 2016).

\section{Metodología}

El proceso de investigación se efectuó desde un paradigma comprensivointerpretativo, bajo una metodología cualitativa, por cuanto propone aproximarse a una realidad desde las comprensiones-significaciones de los propios sujetos que participan del campo objeto de investigación (Flick, 2012). Como método se empleó la Fenomenologia Hermenéutica (van Manen, 2003), porque el interés principal estuvo centrado en lograr la comprensión del significado esencial de los fenómenos, su sentido y la importancia que estos tienen en el propósito del contexto de aplicación (Ayala-Carabajo, 2018). Particularmente en este estudio se buscaba lograr una aproximación a los significados que las educadoras de párvulos participantes construyen en torno al juego dentro del proceso educativo de los niños menores de 3 años, desde la cotidianeidad del aula.

Este estudio se realizó en las ciudades de Chillán, ubicada en la Región de Ñuble, y Concepción, perteneciente a la Región del Biobío, ambas localizadas en el centro sur de Chile. Participaron seis educadoras de párvulos, que desempeñan su labor en el Nivel de Sala Cuna (o a 2 años) y Nivel Medio Menor (2 a 3 años) de 
instituciones de atención a la primera infancia. Las profesionales fueron incluidas a partir de los siguientes criterios internos a la investigación: desempeñar su labor con niños menores de tres años y demostrar interés y voluntad de participar en el estudio, lo que fue detectado en dos grupos focales (focus groups), uno en cada región, durante los cuales se invitó a participar a educadoras de párvulos previamente autorizadas por las directoras de salas cuna y jardines infantiles.

Como técnica de producción de información se empleó la entrevista semiestructurada, en tanto se comenzó con un guion previamente definido, pero admitía la formulación de preguntas emergentes para aclarar o profundizar las comprensiones de las participantes. La entrevista se realizó en forma directa, informando sobre el propósito del estudio y asegurando la confidencialidad de los datos. El discurso fue grabado en formato de audio y posteriormente transcrito en forma literal.

Para llevar a cabo el análisis se optó por un proceso de categorización mixto, vale decir, deductivo e inductivo. Desde la perspectiva deductiva se definieron apriorísticamente las siguientes categorias teóricas: concepto de juego, valoración del juego e intencionalidad otorgada al juego. Desde el punto de vista inductivo, se optó por el levantamiento de una categoría desde el discurso a partir de la condensación del significado de base fenomenológica, entendida como el "resumen de los significados expresados por los entrevistados en formulaciones más breves" (Kvale, 2011, p. 140) y la interpretación de dichos significados. Este análisis permitió establecer la categoría denominada implementación del juego en base a lo señalado por las educadoras en sus discursos (ver Figura 1). Para el análisis de los datos se empleó el software Atlas.ti v. 8.

Figura 1. Red de categorías empleadas para el análisis de los datos

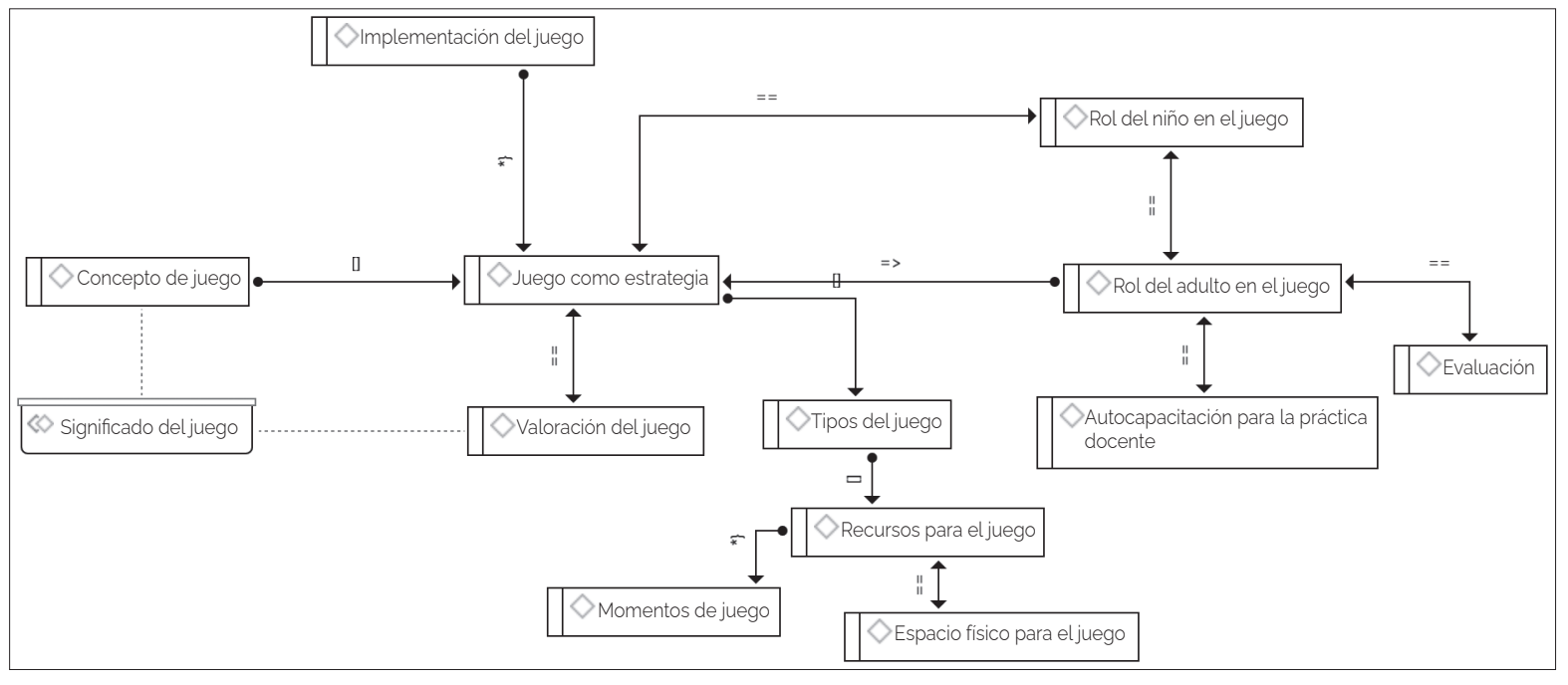

Fuente: Elaboración propia 


\section{Resultados}

Se presentan los principales resultados obtenidos desde las voces de las educadoras de párvulos que participaron en el estudio, organizados a la base de las categorias teóricas empleadas para el análisis de la información, con sus correspondientes códigos y las relaciones establecidas entre estos.

\section{Significado otorgado al juego}

\section{Concepto de juego}

Desde las estructuras de conciencia elaboradas por las educadoras, el juego es concebido como una actividad innata, libre y autodirigida de los párvulos, por lo tanto, bajo esta perspectiva serian ellos quienes le otorgan intencionalidad a la acción de jugar. Es así como las educadoras entrevistadas señalan lo siguiente:

\section{"El juego para mí es la interacción innata que se da entre los niños, con un propósito en común que hace que ellos se asocien para producir algo". (E1) \\ "El juego es una instancia que desarrollan los niños de forma libre. espontánea y decidida por ellos mismos, que a veces ellos mismos le dan la intencionalidad que sea de forma de juego". (E3) \\ "El juego es una actividad natural, que es propia de los niños, en donde ellos se desenvuelven de manera natural también". (E6)}

No obstante lo anterior se puede apreciar que al llevar a las educadoras hacia la búsqueda de la profundización sobre la conceptualización que le otorgan al juego, en sus componentes definitorios entrecruzan dos perspectivas distintas en torno a esta actividad. Por un lado, aluden a una acción natural y espontánea de los párvulos, pero por otro lo conciben como una estrategia didáctica válida, intencionada por el adulto y establecida en ciertos momentos de la jornada para favorecer aprendizajes en los infantes, cuyo rol activo estaría siendo asumido por el adulto y el niño solo actuaría como participante. Esto puede ser sustentado cuando exponen lo siguiente:

"Eljuego es la estrategia principal que utilizamos especialmente en este nivel de sala cuna para que el niño aprenda, es el medio que utilizamos para lograr un aprendizaje en los niños y niñas". (E2)

"En los periodos permanentes se trabaja con intencionalidad pedagógica, no con aprendizaje esperado, y en las variables también se desarrolla el juego en la metodología, trabajando con grupos y con material más variado, pero igual bajo la conducción en ese sentido del adulto". (E1)

"La canasta del tesoro es una estrategia, claro. La canasta del tesoro, el juego heurístico también, pero aparte nos enfocamos harto en lo sensorial, les ofrecemos tal vez por separado estimulación visual con diferentes tipos de imágenes o colores, luces, aromas, texturas, cosas asi". (E6) 


\section{Implementación del juego}

Desde el punto de vista de la implementación del juego considerado como estrategia didáctica, en el discurso de las educadoras se destaca que el denominado juego heurístico sería uno de los principales que se implementan o al menos intentan hacerlo de manera adaptada con los párvulos.

A juicio de las educadoras, por un lado este juego aportaría beneficios tales como la espontaneidad y la fluidez que ofrece para la generación de otras instancias de juego en la interacción de los niños con los materiales que son puestos a su disposición. Incluso algunas educadoras señalan emplear en este tipo de actividad materiales que se enmarcan en los postulados del curriculum Waldorf. Ello puede ser apreciado en las siguientes citas:

"Eljuego heurístico idealmente en sala cuna y el niño aprende solito, nosotros nos damos cuenta cómo empieza a clasificar, a ordenar, a agrupar". (E3)

"Yo hago como una adaptación del juego heuristico, porque el mismo tema del espacio me cuesta un poco desarrollarlo como tal, como está implementado teóricamente, pero el juego heurístico es una experiencia súper espontánea y natural y fluida que genera otras instancias y depende del nivel en el que se haga", (E4)

"Nosotros estamos utilizando el juego heurístico, nosotros presentamos material hilado con el currículum de Waldorf, que tiene que ver con trabajar con materiales nobles, entonces presentamos a los niños, cuando ellos vuelven del patio, un set de canastos donde tienen materiales que son conos de madera, algunos vasitos de plástico, algún tipo de material, entonces ellos cuando llegan al material no hay nada más que los distraiga. Los más chiquititos están en la etapa de descubrir y los más grandes ya clasifican, ordenan, juegan". (E2)

Por otro lado, las educadoras señalan emplear también otros tipos de juegos, entre ellos la promoción del juego simbólico con elementos y situaciones familiares para los párvulos, el juego en rincones o áreas de aprendizaje y algunas actividades corporales de carácter lúdico. Es asi como plantean lo siguiente:

"El juego de áreas son aprendizajes en la planificación y se orienta a que los niños puedan escoger el material que ellos quieran. Generalmente es la representación y lo que más les gusta hacer es jugar con bebés". (E2)

"Los juegos de dedo les encantan a los chiquillos, son tan pequeños, pero igual lo hacen porque la ven a una. En el fondo es más por imitación". (E5)

"Juegos como más domésticos, más caseros, más locales, por ejemplo, la misma casa, el supermercado que lo disfrutan mucho. Hicimos el supermercado hace poco y como lo haciamos por primera vez lo articulamos con el medio menor, entonces fue algo súper lindo porque los niños más grandes les enseñaron a los más pequeños". (E4)

Sumado a lo anterior se destaca que las educadoras han ido transformando sus prácticas pedagógicas vinculadas a la promoción del juego en el aula, aludiendo frente a ello a la apropiación de algunos antecedentes teóricos correspondientes a ciertas modalidades curriculares especificas para el nivel de la educación parvularia. Para el caso de algunas educadoras esta introducción de cambios en sus prácticas responde a la generación de modificaciones curriculares impulsadas 
a nivel institucional más que a decisiones pedagógicas de carácter individual mientras que, para otras, el sustento teórico empleado responde a indagaciones realizadas por iniciativa propia, donde intentan llevar a cabo ese autoconocimiento al ámbito de su acción docente.

"Nuestro jardín ahora está haciendo algunos cambios curriculares, estamos trabajando con la metodología de Waldorf, pasamos por Reggio Emilia, donde se trabaja mucho el juego libre, y nos hemos dedicado por lo mismo a observar esta actividad, las actitudes, sus comportamientos, y el juego tiene muchas oportunidades para el niño, les ofrece muchas instancias de aprendizaje y muchas veces en forma espontánea y natural. Es muy fluida". (E4)

"Juego autónomo del niño. Primeramente el juego autónomo del niño de o a un año, en el nivel de 1 a 2 años están trabajando mucho la corporalidad, están trabajando mucho otros tipos de autonomía porque los niños ya caminan, se desplazan, entonces ya va a cambiar el objetivo del juego, un poco heurístico. Según la edad estamos trabajando con ciertas corrientes. Yo después de lo que leí, Montessori, Waldorf, Pikler... yo dije, ime quedo con Pikler! Me enamoré de Pikler, porque descubri la pólvora, realmente me hace sentido". (E5)

En lo referido a la utilización de recursos o materiales para el juego, las educadoras señalan emplear objetos que son habituales para los niños, los que son solicitados a la familia. También, instrumentos musicales y las manos para seguir ritmos en determinados momentos; inclusive, sus propias ropas o disfraces, a partir de los cuales se promueve el juego simbólico, argumentando que este tipo de recursos son del agrado de ellos, tal como indican las educadoras:

\footnotetext{
"...que jueguen con cosas de la lugaridad, estamos hablando lo mismo que antiguamente, antes deciamos 'Sra. traiga esto, traiga lo otro', instalábamos cosas tan reales con los niños, con cosas habituales". (E5)

"Nosotros utilizamos instrumentos musicales para saludarnos, otras veces utilizamos otros elementos [...], por ejemplo, hay momentos que se golpea la mesa y eso ellos lo disfrutan muchisimo, porque ese juego si que a ellos les gusta", (E3)

"... disfraces o zapatos de ellos, gorros, ropa, etc., porque igual a los chiquillos típico que les gusta vestirse con las ropas de las mamás y preparando el ambiente ahora estamos más en un tema de observación". (E4)
}

Otro de los aspectos relacionados con la implementación del juego está referido al espacio y a los momentos destinados a esta actividad. En cuanto al primero, las participantes del estudio señalan habilitar espacios especificos, por ejemplo, el uso del suelo con colchonetas y cojines, pero se aprecia una clara intencionalidad centrada en favorecer su acercamiento a la lectura. Llama incluso la atención que se haga alusión al Plan Nacional de Lectura para párvulos menores de tres años. Asimismo se destaca que una de ellas habilita un espacio vertical con objetos sensoriales pero este no se intencionaría concretamente hacia el juego porque, al decir de la educadora, los niños pueden hacer uso del mismo precisamente cuando no quieren jugar. En cuanto a los momentos destinados para el juego se evidencian ciertas divergencias en los discursos, pues mientras una educadora señala que desde que los párvulos llegan al aula comienzan a jugar a lo largo de toda la jornada, otras han definido como momento para el juego cuando salen al patio, donde se promueven actividades orientadas a favorecer principalmente la motricidad gruesa. Al respecto, exponen lo siguiente: 
"...un muro sensorial con muchas cosas que los niños exploren, que toquen ahi, hay luces, hay llaves, sonidos y cosas, entonces, los que no quieren jugar, que exploren ahí". (E5)

"Tenemos como un espacio habilitado que es más acogedor, según nuestra mirada, y que a ellos les gusta estar, están con colchonetas, están con cojines y pueden libremente jugar a leer, les encanta jugar a leer y siguen la lectura con el dedo". (E2)

"Momento del patio en el que tenemos distintas actividades, sean de equilibrio, físicas, motoras, libres; pero también nosotros tenemos nuestras actividades variables que es lo que desarrollamos. Realizamos dos actividades variables durante el día, una en la mañana y una en la tarde y esto también va complementado con lo que es el Plan Nacional de Lectura, que eso también ellos lo desarrollan todos los dias". (E4)

En cuanto a los roles asumidos por los infantes y adultos en el juego, desde el discurso de las educadoras serían los niños quienes asumirian un rol activo, generando sus propios juegos y actuando libremente dentro de estos, pero las educadoras advierten que dicho rol solo se habría comenzado a promover desde hace un corto tiempo. En este sentido indican que:

"el protagonismo cien por ciento, sí, ellos son los que deciden acá, ellos son los que deciden de qué manera lo utilizamos, nosotros estamos con ellos". (E3)

"protagonista, cien por ciento, súper activo, como yo le dije, he aprendido a valorar más las instancias de juego, no con tanta formalidad de 'vamos a trabajar', dejarlos un poco más libres". (E4)

"Bueno, ellos son y tienen que ser los protagonistas, hay momentos en que de pronto puede que no nos demos cuenta y con tanta indicación lo pasamos a segundo plano, porque eso pasa, pero nuestra mirada durante este año ha sido que él sea el protagonista". (E2)

Sumado a lo anterior, desde las voces de las educadoras ellas ejercerian los roles de observadoras y mediadoras, pero este último principalmente asociado a la resolución de algún conflicto. Llama la atención la reflexión crítica que hacen algunas de ellas en torno a su actuación como mediadoras, señalando que por momentos dicho rol se ha caracterizado más por caer en el intervencionismo dentro del juego que por constituirse efectivamente en una acción oportuna orientada a prestarles cierto tipo de ayuda, en el caso de ser requerida, para el logro de algún tipo de aprendizaje. Al respecto, exponen lo siguiente:

"Los dejamos ser solamente a los niños, teniendo una intervención muy mínima cuando los pequeños nos invitan a algo o a darle algún tipo de respuesta, a también mediar cuando hay algún conflicto". (E6)

"Siempre con un adulto mediando ante conflicto y todo, pero de acuerdo con los intereses de ellos y los juguetes, los materiales también son dirigidos de acuerdo con sus intereses". (E1)

"En general siempre ha sido como de mediación, pero también con este proceso que estamos haciendo de reflexión nos hemos dado cuenta de que no siempre hacemos bien la mediación, que de repente interrumpimos, más que mediar a veces cortamos o interrumpimos, desviamos la atención del niño". (E4) 
La reflexión crítica que se evidencia en algunas educadoras puede haberse visto motivada a partir de la capacitación o autocapacitación que han llevado a cabo. Uno de los principales referentes teóricos validados ha sido la metodología Pikler, lo que puede evidenciarse cuando exponen que:

"Leer y buscar de Pikler, eso me permitió cambiar un poco las prácticas pedagógicas, y eso uno tiene que cambiar, uno tiene que redireccionar, realmente uno antes no lo hacía tan bien". (E5)

"Estamos trabajando la libertad de movimiento y juegos libres espontáneos a través de su propio juego, eso estamos trabajando, porque hemos leido bastante de Pikler". (E4).

Finalmente, en lo que respecta a la implementación del juego, las educadoras también señalan que hacen uso de la observación como procedimiento para evaluar los logros en los aprendizajes quevan adquiriendo los párvulos, empleando para ello hojas de registro con información de tipo cualitativa, en algunos casos diseñadas por ellas mismas. A este respecto señalan que:

"entonces nosotros después vamos observando y vamos viendo qué aprendizajes va logrando y es integral, porque desde la comunicación, desde la convivencia hasta el lógico matemático, que es el aprendizaje, qué más podemos rescatar de este juego heuristico". (E2)

"lo más importante es cuando ocurre algún logro, nosotras lo registramos. Lo registramos en el panel de evaluación cualitativa". (E5)

"nosotros nos sentamos en un rinconcito solamente a registrar, yo a las chiquillas les elaboré un instrumento para anotar los registros y cada una tiene hojitas de esas y ahi vemos y vamos registrando, de repente en un cuaderno". (E4)

\section{Valoración del juego}

Se evidencia una significativa valoración del juego por parte de las educadoras participantes. Al decir de ellas, esta actividad natural de los párvulos les ofrece múltiples alternativas de aprendizaje, donde destacan las dimensiones cognitivas y emocionales y, en estas últimas, valoran las oportunidades de socialización que ofrece como producto de las interacciones que logran generar cuando juegan. Consideran que el juego promueve, asimismo, la autorregulación en los párvulos y la capacidad para tomar decisiones de acuerdo con sus intereses. Para una de las educadoras, inclusive, la acción de jugar estaría asociada a las condiciones de salud que podría estar presentando el niño en un determinado momento, tal como se expresa aquí:

"A través del juego el niño es libre, escoge, decide y busca su aprendizaje de acuerdo a sus posibilidades, de acuerdo a su interés, de acuerdo a su tiempo, y asi el niño logra internalizar el aprendizaje porque lo hace de acuerdo a lo que él quiere hacer, no de lo que el adulto le guia". (E2)

"La esencia del niño es esa: jugar con lo habitual, con lo conocido, con lo simple y aparte que yo siempre he pensado que al niño que no juega, que no explora, algo le pasa. Yo les digo, 'chiquillas ojo, algo tiene este niño, está raro o anda decaido o anda incubando alguna cosa'". (E5) 
"Eljuego es muy significativo para el desarrollo del aprendizaje, porque todos sabemos que los niños aprenden jugando, entonces la interacción con sus pares, con los adultos de referencia, con el material que se les da para el juego, es la principal actividad para generar las interacciones cognitivas desafiantes en los niños y afectivas también, que los invite al descubrir, al explorar, al imaginar cosas". (E1)

Asimismo se reconoce que el juego en la educación parvularia fue perdiendo legitimidad porque se fue dando paso a metodologías de enseñanza que llevaron a la escolarización temprana de los niños a partir del uso reiterado de recursos más pertinentes a los niveles educativos superiores. Estas prácticas se fueron reproduciendo, validando y normalizando por las propias educadoras, pero se reconoce que la participación en instancias de capacitación les ha permitido valorar el énfasis que se le está otorgando actualmente a esta actividad en el proceso de enseñanza y aprendizaje de los párvulos. No obstante, el argumento dado a esta valoración responde más a una apreciación subjetiva que a una argumentación teórica y/o empírica en función de la relevancia crucial que tiene el juego para el desarrollo integral de los infantes. Dicha valoración se enmarca, incluso, en las posibilidades que ofrece esta actividad como estrategia didáctica y no como una práctica natural y esencial de los niños. A este respecto, las educadoras señalan que:

"Antes no se jugaba, teniamos que conseguir aprendizajes. Ojalá que no siga siendo el adulto el protagonista (era el protagonista), porque era el que guiaba, orientaba, mediaba, pero ahora no". (E2)

"En relación con los juegos, hay un cambio... hay un cambio en lo que es educación parvularia. Yo recuerdo no hace mucho tiempo teníamos a los niños sentados trabajando con lápiz, con plantilla, particularmente nunca he sido muy amiga de las plantillas, de hecho las he trabajado seguramente un par de veces. Pero me gusta este énfasis que le da nuestra institución al juego, a estas capacitaciones que nos han hecho como educadoras y como equipo, en general, a tener al juego como estrategia principal". (E2)

"Creo que cuando los precursores se basaron en el juego y en toda la intención educativa que tiene el juego en educación parvularia, pero cuando lo vuelven a reinstalar y nos vuelven a decir, ioye, mira, el juego!, en el juego está todo, todo, la autonomía, la identidad, está todo. Por lo tanto, nosotras las educadoras tenemos que darle el sentido que se merece el juego". (E5)

\section{Discusión}

En la búsqueda de los significados que le atribuyen educadoras de párvulos al juego en los primeros tres años de vida, un primer aspecto a discutir está relacionado con la concepción sobre esta actividad que han ido construyendo a lo largo de su práctica pedagógica. Al respecto, en su conceptualización se visualizan dos configuraciones que tienen matices diferenciadores. Por una parte se define como una actividad natural, espontánea y autodirigida por los pequeños mientras que, por otra, hacen referencia a la principal estrategia didáctica empleada para favorecer aprendizajes en ellos. Ambas perspectivas resultan ser coincidentes con lo expuesto en las Bases Curriculares de la Educación Parvularia (Mineduc, 2018), por cuanto se señala que el juego "se refiere tanto a una actividad natural del niño o niña como a una estrategia pedagógica privilegiada". (p. 32) 
No obstante la claridad conceptual que poseen las educadoras sobre el juego, llama la atención que dicho significado, posicionado a nivel de conciencia, cambia de sentido al momento de su implementación. La promoción deljuego espontáneo o autodeterminado por el párvulo queda relegado a un nivel inferior, dando así lugar a una frecuente utilización de esta actividad como estrategia didáctica, cuya intencionalidad es claramente definida por el adulto, estableciendo momentos especificos para actividades más bien de carácter lúdico donde el rol de los párvulos queda condicionado a las orientaciones o presentaciones que realiza la educadora. Bajo este tipo de actuaciones, el sentido del juego como actividad natural en los primeros años de vida se instrumentaliza, quedando condicionado a lo que la educadora planifica y determina, perdiendo de este modo su carácter de actividad natural. Esto confirma lo señalado por Durán y Pulido (2018) cuando exponen que muchas maestras de educación infantil entienden la relevancia del juego en la infancia, pero "siguen desarrollando acciones que lo limitan, restringen o instrumentalizan". (p. 227)

La instrumentalización del juego también puede ser visualizada a partir de la definición de tiempos específicos dentro de la jornada para que los niños jueguen, ya sea en experiencias de aprendizaje intencionadas por el adulto o en forma libre, donde aquellas se vinculan más a momentos de entretención o de recreo. Y si bien la mayoría de las educadoras dentro de su discurso hace referencia a algunos sustentos teóricos como Pikler o Waldorf bajo los cuales promueven el juego, llama la atención que sea un discurso reiterativo entre ellas pero que se queda solo a nivel declarativo y no de su acción, pues los postulados de estos enfoques metodológicos para la educación infantil se pierden al momento de su implementación. Algo similar ocurre con el denominado juego heurístico, ampliamente señalado por las educadoras, pero que se queda a nivel de intención, vale decir, un querer implementarlo, por cuanto ajuicio de las mismas las condiciones de la realidad serian un factor que obstaculiza su implementación siguiendo los antecedentes teóricos que sustentan esta metodología (Goldschmied, 1990).

El acto declarativo en torno al juego evidenciado en las educadoras puede ser explicado desde dos perspectivas. La primera, a partir de la asistencia de estas profesionales a capacitaciones o seminarios promovidos desde las propias instituciones en las cuales se desempeñan. Durante estas instancias formativas dichas educadoras se han apropiado mayoritariamente de antecedentes teóricos que son reproducidos en sus discursos, cuya transferencia a la práctica se lleva a cabo bajo concepciones epistemológicas y metodológicas tradicionales. El rol del párvulo en la realidad del aula continúa visualizándose en un nivel inferior al del adulto, existe una tensión entre el discurso y la acción que lleva a sostener que estas capacitaciones no han tenido mayor incidencia en la transformación de la acción pedagógica, fundamentalmente en lo que respecta a la promoción del juego en los párvulos bajo una concepción que resignifique y releve esta actividad natural del ser humano como tal. La segunda puede ser explicada a partir de las subjetividades de las educadoras, quienes interpretan los antecedentes teóricos, empíricos y los fenómenos educativos en general en base a sus propias creencias, vivencias y construcciones pedagógicas, donde el juego es valorado como la principal estrategia didáctica y, por consiguiente, bajo esta comprensión y significación sería el adulto quien tiene el deber de intencionar esta actividad, tanto en las experiencias de aprendizaje que implementa a la base de su planificación didáctica como en la determinación de los momentos y de la estructuración de los espacios para el juego. Por consiguiente, se reitera que la actuación de la educadora se sostiene en base a un sentido instrumental del juego (Durán y Pulido, 2018). 


\section{Conclusiones}

El juego, sin duda, contribuye de manera significativa a todos los ámbitos del desarrollo infantil desde edades muy tempranas, lo que es avalado tanto por la teoria existente sobre el desarrollo biopsicosocial como por las políticas promulgadas para la infancia a nivel internacional. Por consiguiente, resulta necesario aproximarse a las significaciones que las educadoras construyen en torno a esta acción relevante para el proceso de aprendizaje de los párvulos, tanto desde sus actos declarativos como desde su acción pedagógica, pues son ellas, los adultos, quienes interactúan con los menores al menos durante siete horas al día en el caso de los niños que asisten a jornada completa en salas cuna y jardines infantiles de instituciones que tienen reconocimiento del Estado a nivel nacional.

En relación a lo anterior es importante señalar que desde el punto de vista ético y pedagógico uno de los factores relevantes dentro del proceso educativo en los párvulos corresponde a la calidad del ambiente en el aula que las educadoras logran generar, tanto en lo referido a las interacciones personales como en lo relativo a la determinación de los aspectos físicos y temporales destinados a las situaciones de aprendizaje. El ambiente del aula hoy en día es concebido, incluso, como el tercer educador, por cuanto tiene repercusiones -positivas o negativasen el proceso de aprendizaje y en el desarrollo de los niños. Al respecto es relevante destacar que las situaciones educativas que se generen dentro del aula, fundamentalmente en los tres primeros años de vida, son clave para el aprendizaje y desarrollo posterior, por lo que deberian focalizarse en la promoción del juego en todas sus dimensiones y en sus formas diversas de expresión. Por consiguiente, el rol del adulto requiere orientarse principalmente a la generación de las condiciones óptimas que lo posibiliten, a la observación y lectura constante de las actuaciones de los párvulos en sus juegos y, por sobre todo, al respeto profundo de sus intereses, acciones y condiciones innatas según su etapa de desarrollo. Estos aspectos han sido olvidados por muchas educadoras en nuestro país, quienes han implementado y reproducido modelos escolarizantes desde edades muy tempranas, condicionando a los párvulos a experiencias de aprendizaje y a actividades rígidas donde las posibilidades de juego espontáneo y de libre expresión se han visto coartadas.

Finalmente, consideramos necesario continuar en la línea de investigación de las prácticas pedagógicas que implementan educadoras de párvulos en lo que respecta a la promoción del juego en los niveles educativos siguientes, vale decir, Nivel Medio Mayor (3 a 4 años) y Niveles de Transición (4 a 6 años). El juego corresponde a una actividad de aprendizaje innata de los niños, que trasciende en el tiempo y que se va transformando según la etapa de desarrollo en la que se encuentren.

\footnotetext{
Notas:

'Este artículo presenta resultados del proyecto de investigación regular titulado "Sentido y significado que le atribuye la educadora de párvulos al juego en el nivel sala cuna" (Código 172523 3/r), financiado por la Dirección de Investigación de la Universidad del Bío-Bío. Chile.

Aprobación final del artículo: editora responsable Mag. Verónica Zorrilla de San Martín.

Contribución de autoría: la concepción del trabajo cientíico fue realizada por todas las autoras. La recolección de datos también estuvo a cargo de todas las autoras, mientras que la interpretación y el análisis estuvo a cargo de Carolina Flores Lueg. La redacción del manuscrito fue realizada por Carmen Mena Bastias y Carolina Flores Lueg. Todas las autoras revisaron y aprobaron el contenido final.
} 


\section{Bibliografía}

AYALA-CARABAJO, R. (2018). La relación pedagógica: en las fuentes de la experiencia educativa con van Manen. Revista Complutense de Educación, 29(1), 27-41. http://dx.doi.org/10.5209/RCED.51925

BORGHI, Q. (2010). Educar en el o a 3. La Práctica Reflexiva en los nidi dinfanzia. ILa Práctica Reflexiva en las escuelas de párvulos]. Barcelona, España: Graó.

BRAVO, A. Y MORALES, H. (2012). Caracterización de educadoras de párvulos que se desempeñan en el nivel sala cuna en una muestra de jardines infantiles de Concepción, Chile. Revista Electrónica Actualidades Investigativas en Educación, 12(2), 1-25. http://www.redalyc.org/pdf/447/4472343700g.pdf

BROOKER, L. (2013). El papel del juego en el desarrollo. En Brooker, L. y Woodhead, M. (Eds.). El derecho al juego. Revista La Primera Infancia en Perspectiva, 9, 17-18. http://iin.oea.org/pdf-iin/RH/El-derecho-al-juego.pdf

COMITÉ SOBRE LOS DERECHOS DEL NIÑO DE LAS NACIONES UNIDAS. (2013). http://goo.gl/GblLws

Durán, S. y Pulido, J. (2018). Creencias de maestras respecto al juego en educación inicial, trazos para su investigación. Pedagogía y Saberes, 49, 228-234. http:// www.scielo.org.co/pdf/ppo/n19/2011-804X-ppo-19-00225.pdf

FLICK, U. (2012). Introducción a la investigación cualitativa. Madrid: Ediciones Morata.

FUSTÉ, S. Y BONASTRE, M. (2014). Psicomotricidad y vida cotidiana (o a 3 años). Barcelona: Graó

GOLDSCHMIED, E. (1990). El juego heuristico: una actividad del segundo año de vida. Infancia: educar de o a 6 años, 4, 15-20. https://www.rosasensat.org/ magazines/in-fan-cia/4/icas_4.pdf

HERRÁN, E. (2013). La educación Pikler-Lóckzy. Cuando educar empieza por cuidar. Revista Latinoamericana de Educación Infantil, 2(3), 37-56. https://addi. ehu.es/handle/10810/11212

KATZ, L. (2005). Perspectivas educativas en la primera infancia. Santiago: Ediciones Lom.

KVALE, S. (2011). Las entrevistas en Investigación Cualitativa. Madrid: Ediciones Morata.

LANSDOWN, G. (2013). ¿Qué es el juego? El derecho de los niños al juego. En Brooker, L. y Woodhead, M. (Eds.). El Derecho al Juego. Revista La Primera Infancia en Perspectiva, 9, 1-2. https://bernardvanleer.org/app/uploads/2016/03/Elderecho-al-juegob617.pdf

LÓPEZ DE MATURANA, D. (2017). El juego libre en el desarrollo infantil En JUNJIOMEP, Nuevos ambientes de aprendizaje en Educación Parvularia. Ponencias del VII Congreso Latinoamericano: JUNJI-OMEP Nuevos ambientes de aprendizaje en Educación Parvularia de o a 3 años. (33-37). Santiago de Chile: EJ ediciones de la JUNJI. https://Www.junji.gob.cl/wp-content/uploads/2017/08/LibroOMEP.pdf 
MINISTERIO DE EDUCACIÓN DE CHILE- MINEDUC (2018). Bases Curriculares de la Educación Parvularia. Santiago: Ministerio de Educación de Chile.

MINISTERIO DE EDUCACIÓN DE CHILE-MINEDUC (2014). Estado del Arte de la Educación Parvularia en Chile. Santiago: Ministerio de Educación de Chile.

MINISTERIO DE EDUCACIÓN DE CHILE-MINEDUC (2001). Bases Curriculares de la Educación parvularia. Santiago: Ministerio de Educación de Chile

MINISTERIO DE RELACIONES EXTERIORES DE CHILE (1990). Decreto 830. Promulga Convención sobre los Derechos del Niño. https://www.leychile.cl/ Navegar?idNorma=15824

ORMAZA, A. (2016). Observación de la actividad autónoma infantil en la escuela infantilPikler-Lóczy desde la metodologia observacional. Unestudio exploratorio. En Rodríguez, A., Romero, A. y Martinez, I. (Ed.). XXIII Jornadas de Investigación en Psicodidáctica/XXIII Psikodidaktikako Ikerkuntza Jardunaldiak (pp. 2-23). Bilbao: Universidad del Pais Vasco. https://www.researchgate.net/profile/Jon_Martin7/ publication/320980050_Flow_egoera_bertsolarien_sormenean_State_of flow_in_the_creativity_of_bertsolaris/links/5a057e28458515eddb8661c3/ Flow-egoera-bertsolarien-sormenean-State-of-flow-in-the-creativity-ofbertsolaris.pdf\#page $=10$

PIKLER, E. (1984). Moverse en libertad. Desarrollo de la motricidad global. Madrid: NARCEA.

QUIROGA, P. (2014). La pedagogía Waldorf: origen, consolidación internacional y principios educativos. Utopia y educación. En Hernández Huerta, J. L., Quintano Nieto, J. y Ortega Gaite, S. (coords.). (2014). Utopia y Educación. Ensayos y Estudios (pp. 55-77). Salamanca: FahrenHouse. https://dialnet.unirioja.es/servlet/ articulo? codigo $=5920789$

QUIROGA, P. E IGELMO, J. (2013). La pedagogía Waldorf y el juego en el jardín de infancia. Una propuesta teórica singular, Bordón, 65(1), 79-92, https://recyt.fecyt. es/index.php/BORDON/article/view/brp.2013.65106/11374

RAMIIREZ-ABRAHAMS, P., PATIÑO-MORA, V. Y GAMBOA-VÁSQUEZ, E. (2014). La educación temprana para niños y niñas del nacimiento a los 3 años: Tres perspectivas de análisis. Revista Electrónica Educare, 18(3), 67-90. http://dx.doi. org/10.15359/ree.18-3.5

SARLÉ, P. (2008). Enseñar en clave de juego. Buenos Aires: Noveduc.

STEINER, R. (1973). Anthroposophical Leading Thoughts. IPensamientos antroposóficos principales]. Suiza: Rudolf Steiner Press. https://wn.rsarchive. org/Books/GA026/English/RSP1973/GA026_index.html

STEINER, R. (1997). La educación del niño. Metodología de enseñanza. Madrid: Editorial Rudolf Steiner.

VAN MANEN, M. (2003). Investigación educativa y experiencia vivida. Ciencia humana para una pedagogía de la acción y sensibilidad. Barcelona: Idea Books, S.A. 